\title{
THROMBOSIS OF A MITRAL VALVE PROSTHESIS IN A PATIENT WITH HEPARIN-INDUCED THROMBOCYTOPENIA TYPE II
}

Jaime F. Vazquez-Jimenez, MD, ${ }^{a}$ Uwe Janssens, MD, ${ }^{\mathrm{b}}$ Bernd Sellhaus, MD, ${ }^{\mathrm{c}}$ Benita Hermanns, MD, ${ }^{\mathrm{c}}$ Werner Huegel, MD, ${ }^{\mathrm{a}}$ Peter Hanrath, MD, ${ }^{\mathrm{a}}$ and Bruno J. Messmer, MD, ${ }^{\mathrm{a}}$ Aachen, Germany

Heparin-induced thrombocytopenia (HIT) type II is one of the most devastating but least widely recognized complications of heparin therapy. It is characterized by the tendency to cause thrombocytopenia with associated thrombosis. ${ }^{1}$ The condition typically arises between the 5 th and 14 th days after first exposure to heparin therapy and is usually associated with a platelet count below $100 \times 10^{9} / \mathrm{L}$ or a fall of platelet counts to more than $50 \%$ of the baseline value accompanied by heparin-induced antiplatelet antibodies. These patients are at high risk for severe, mainly venous thromboembolic complications with a mortality of up to $30 \%$. The true incidence of HIT type II is uncertain. A recent report including 332 patients receiving unfractionated heparin found an incidence of $2.7 \% .^{2}$ The purpose of this case report is to alert cardiac surgeons to the risk of cardiac prosthetic valve thrombosis in patients treated with heparin and HIT.

Clinical summary. A 58-year-old woman with a history of mitral and aortic valve replacement in 1975 (Björk-Shiley 21 and $29 \mathrm{~mm}$ valves, Shiley, Inc, Irvine, Calif) and aortic valve re-replacement (St Jude Medical $23 \mathrm{~mm}$ valve, St Jude Medical, Inc, St Paul, Minn) and tricuspid ring annuloplasty (Carpentier-Edwards ring size 34, Baxter Healthcare Corp, Irvine, Calif) in 1991, underwent elective cholecystectomy. Anticoagulant therapy with phenprocoumon (Marcumar; Roche, Germany) was suspended before the operation and switched to intravenous unfractionated heparin-calcium (Calciparin; Sanofi Winthrop, Germany). After the uneventful operation, phenprocoumon was restarted overlapping with intravenous heparin-calcium until an international normalized ratio of 3.0 was reached. Two months later she was readmitted to the cardiology department because of persistent angina pectoris and electrocardiographic signs of anterolateral ischemia. Function of the aortic and mitral prosthetic valves was normal without signs of thrombosis, as shown in the transthoracic echocardiogram. Oral anticoagulant therapy with phenprocoumon was stopped and the patient received

From the Department of Thoracic and Cardiovascular Surgery, ${ }^{\mathrm{a}}$ Medical Clinic I, ${ }^{\mathrm{b}}$ and Department of Pathology, ${ }^{\mathrm{c}}$ University Hospital of RWTH, Aachen, Germany.

Received for publication Sept 3, 1998; accepted for publication June 3, 1999 .

Address for reprints: Jaime F. Vazquez-Jimenez, MD, Department of Thoracic and Cardiovascular Surgery, University Hospital of RWTH Aachen, Pauwelsstr 30, D-52057 Aachen, Germany (E-mail: jvazquez-jimenez@post.klinikum.rwth-aachen.de).

J Thorac Cardiovasc Surg 1999;118:751-3

Copyright (C) 1999 by Mosby, Inc.

0022-5223/99 $\$ 8.00+0 \quad \mathbf{1 2 / 5 4 / 1 0 0 4 0 6}$

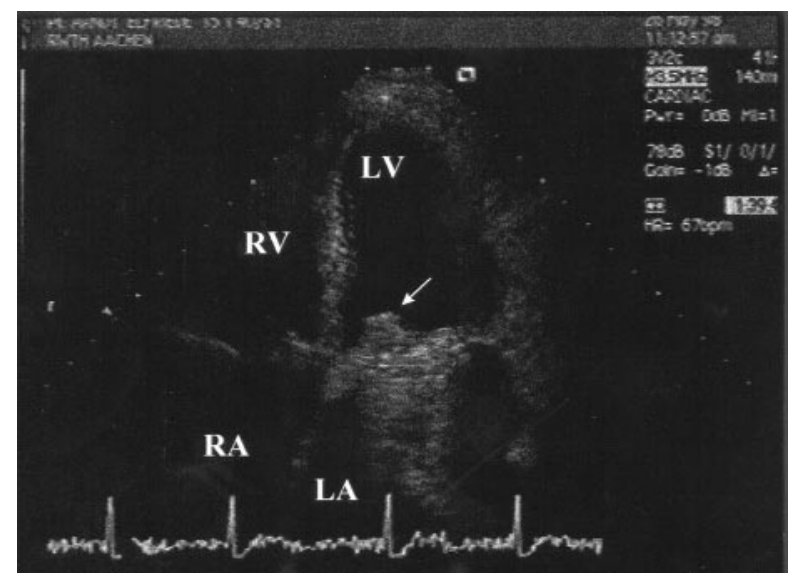

Fig 1. Transthoracic echocardiography (apical 4-chamber view) demonstrating spherical thrombus (arrow) attached to the ventricular side of the mitral valve prosthesis. $L V$, Left ventricle; $L A$, left atrium; $R V$, right ventricle; $R A$, right atrium.

intravenous heparin-calcium again. Catheterization of the right side of the heart 8 days later showed elevated pulmonary artery pressures $(45 / 25 \mathrm{~mm} \mathrm{Hg}$ ) and a mean pulmonary capillary wedge pressure of $25 \mathrm{~mm} \mathrm{Hg}$. A subsequent transthoracic echocardiogram demonstrated subtotal thrombosis of the mitral valve with a spherical thrombus adjacent to the ventricular side of the prosthetic mitral valve (Fig 1) and severely decreased occluder motion. At that time, platelet counts had decreased from $287 \times 10^{9} / \mathrm{L}$ on admission to $156 \times 10^{9} /$ L. Heparin-dependent antibodies were detected by heparin/platelet factor 4 enzyme-linked immunosorbent assay. Therefore heparin-calcium was instantaneously replaced with the recombinant hirudin lepirudin (Refludan; Hoechst Marion Roussel, Germany). Immediately before the operation, a loss of the right radial and brachial artery pulses occurred, suggestive of peripheral embolization.

The patient underwent extracorporeal circulation at hypothermia $\left(28^{\circ} \mathrm{C}\right)$ and cardioplegic arrest during which an ecarin clotting time assay was used to monitor anticoagulation with lepirudin. Besides multiple thrombi in the left atrium, the mitral valve prosthesis was almost completely obstructed with thrombus (Fig 2). The thrombotic formation on the ventricular side of the prosthetic valve had disappeared. The prosthesis and the thrombotic material were removed and a new mitral prosthesis was implanted $(29 \mathrm{~mm}$ St Jude Medical). After extracorporeal circulation, right 


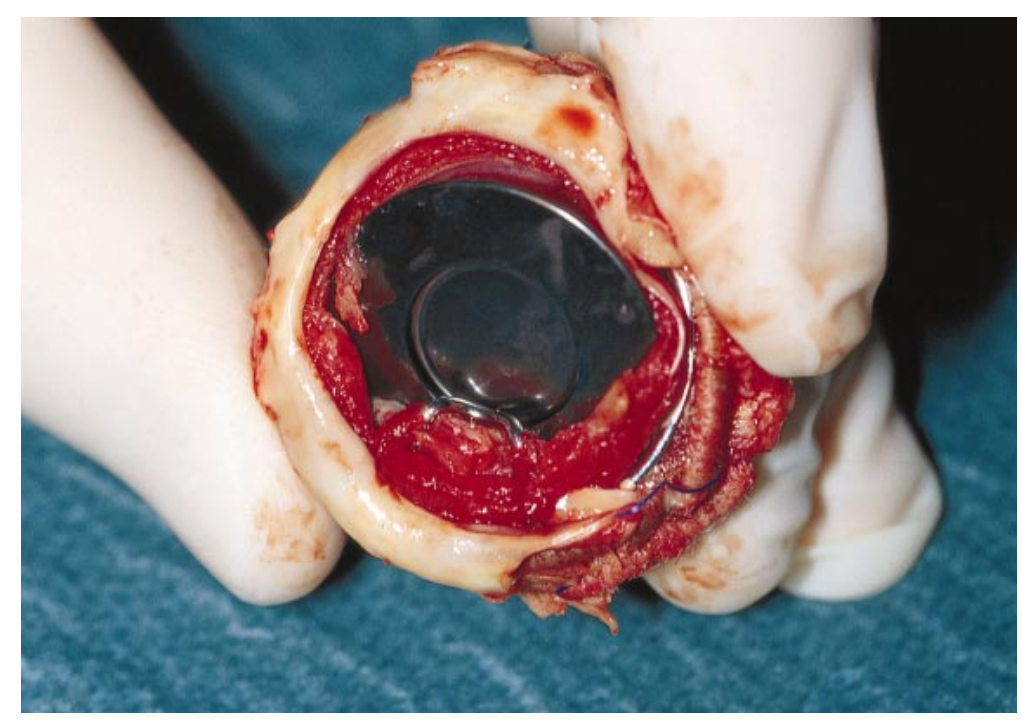

Fig 2. Mitral valve prosthesis (Björk-Shiley $29 \mathrm{~mm}$ ) showing almost complete thrombosis. Note the "white thrombus" at 8 hours.

brachial artery embolectomy was performed and revealed a "white clot." The histomorphologic examination of the thrombotic material showed a structure similar to onion skin with markedly decreased fibrin content resulting in a loose and wide-meshed fibrin web. Immunohistochemical staining revealed markedly decreased fibrin content and a high amount of immunoglobulin G.

The patient recovered well from the operation. The postoperative blood loss was $1120 \mathrm{~mL}$ in the first 5 hours and 130 $\mathrm{mL}$ in the next 15 hours. On the first postoperative day the chest drains were removed. She was further treated with lepirudin, which was later replaced with phenprocoumon. Platelet counts returned to normal values on the 6th postoperative day and we observed no further thromboembolic event. On the 20th postoperative day she was discharged home.

Conclusions. This case report clearly demonstrates the urgent need for rapid recognition of HIT, because this sideeffect of heparin therapy may lead to severe, life-threatening thromboembolic complications. Given the large number of patients with coronary artery disease or valvulopathies undergoing cardiovascular operations and concomitant heparin therapy, close monitoring of platelet counts is mandatory. A drop of platelet counts below $100 \times 10^{9} / \mathrm{L}$ or to more than $50 \%$ of baseline values is highly suggestive of the presence of heparin-induced antibodies, which should be confirmed by laboratory testing. We observed a $46 \%$ decrease of platelet counts in our patient on the 9th day of heparin treatment, accompanied by a severe thrombosis of the mechanical mitral valve prosthesis. So far there is no evidence that re-exposure to heparin therapy leads to earlier formation of heparininduced antibodies and respective clinical manifestation of HIT. However, Warkentin and associates ${ }^{2}$ reported on 2 patients in whom neurologic symptoms and thrombocytope- nia developed shortly after re-exposure to heparin, indicating that these patients may have been sensitized. ${ }^{3}$ HIT may develop sooner after institution of therapy in patients preexposed to heparin than in those receiving heparin for the first time, suggestive of an anamnestic response. ${ }^{4}$ However, almost all of these reported events have occurred within days to weeks of the index exposure, when the heparin-induced immunoglobulin $\mathrm{G}$ was still detectable in the circulation. Our patient received intravenous heparin within this time frame before the manifestation of HIT. Therefore we cannot exclude the presence of a heparin-induced antibody on admission and re-exposure to heparin. On the other hand, thrombocytopenia and clinical manifestation of HIT did not develop earlier, consistent with a primary immune response and absence of immunologic memory.

Any thromboembolic complication during heparin therapy should prompt the clinician to exclude HIT, since heparinrelated thrombosis may occur despite normal platelet counts ${ }^{5}$ or precede thrombocytopenia in up to $30 \%$ of cases. ${ }^{6}$ Furthermore, patients with a mechanical valve prosthesis and HIT may be at high risk for local thrombotic complications since platelet activation, adhesion, and aggregation caused by contact of platelets to artificial surfaces may be enhanced in the presence of heparin-induced antibodies. Although these patients require sustained parenteral anticoagulation either due to their underlying disease or due to the acquired thrombotic complications, immediate heparin cessation is obligatory. Therefore alternative anticoagulants, such as low-molecularweight heparin, heparinoids, argatroban (a small-molecule, reversible, direct thrombin inhibitor), and recombinant hirudin, as well as several other drugs, have been introduced in the treatment of patients with HIT. Low-molecular-weight heparin and heparinoids resemble heparin's immunologic structure and can cross-react with the HIT antibody. In con- 
trast to these agents, argatroban and lepirudin bear no structural or immunologic resemblance to heparin and therefore cannot induce platelet aggregation through HIT antibodies. ${ }^{3}$ Lepirudin is the most potent and specific thrombin inhibitor currently known and is actually manufactured for clinical purposes in a recombinant technique. It acts directly on thrombin, blocking its complete catalytic activity independently of cofactors such as antithrombin III. Therefore therapy with lepirudin seemed reasonable in our patient and provided sufficient anticoagulation, minimizing the risk of further thromboembolic complications caused by the presence of heparin-induced antibodies. It should be pointed out that neither the activated partial thromboplastin time nor the activated clotting time is suitable for monitoring lepirudin as an anticoagulant in extracorporeal circulation. ${ }^{7}$ However, the ecarin clotting time assay used in our patient during cardiopulmonary bypass allowed safe surveillance of the anticoagulant activity of lepirudin.

There is no antidote for lepirudin. Moreover, patients with renal insufficiency or acute renal failure are at high risk for an accidental overdose, because lepirudin is eliminated predominantly via the kidneys. Therefore treatment of bleeding complications in these patients may be problematic. Despite that, we did not observe any major bleeding in our patient.

To the best of our knowledge this may be the first report of a severe mechanical valve thrombosis in a patient with proven HIT. The clinical course of our patient underscores the importance of close monitoring of platelet counts, as well as immediate cessation of heparin therapy in the face of thromboembolic complications, and laboratory approval of heparin-induced antibodies.

\section{REFERENCES}

1. Warkentin TE, Chong BH, Greinacher A. Heparin-induced thrombocytopenia: towards consensus. Thromb Haemost 1998; 79:1-7.

2. Warkentin TE, Levine MN, Hirsh J, Horsewood P, Roberts RS, Gent M, et al. Heparin-induced thrombocytopenia in patients treated with low- molecular-weight heparin or unfractionated heparin. N Engl J Med 1995;332:1330-5.

3. Warkentin TE, Hirte HW, Anderson DR, Wilson WE, O'Connell GJ, Lo RC. Transient global amnesia associated with acute heparin-induced thrombocytopenia. Am J Med 1994;97:489-91.

4. Brieger DB, Mak K-H, Kottke-Marchant K, Topol EJ. Heparininduced thrombocytopenia. J Am Coll Cardiol 1998;31:1449-59.

5. Hach-Wunderle V, Kainer K, Salzmann G, Muller-Berghaus G, Potzsch B. Heparin-related thrombosis despite normal platelet counts in vascular surgery. Am J Surg 1997;173:117-9.

6. Greinacher A. Heparin-induced thrombocytopenia. Internist 1996;37:1172-8.

7. Potzsch B, Madlener K, Seelig C, Riess CF, Greinacher A, Muller-Berghaus G. Monitoring of r-hirudin anticoagulation during cardiopulmonary bypass-assessment of the whole blood ecarin clotting time. Thromb Haemost 1997;77:920-5. 